\title{
FORMAS PRONOMINAIS ALTERNANTES NA EXPRESSÃO DE P4 NA COSTA DA LAGOA, FLORIANÓPOLIS - SANTA CATARINA
}

\section{PRONOMINAL ALTERNATING FORMS IN P4 EXPRESSION IN COSTA DA LAGOA, FLORIANÓPOLIS-SANTA CATARINA}

\section{Maria Cristina Macedo Alencar}

\author{
Doutoranda em Linguística pela Universidade Federal de Santa Catarina \\ Mestre em Linguística Aplicada pela Universidade Estadual de Campinas \\ Professora da Universidade Federal do Sul e Sudeste do Pará \\ E-mail: cristinaufpa@yahoo.com.br
}

Ezra Alberto Chambal Nhampoca

Doutoranda em Linguística pela Universidade Federal de Santa Catarina

Mestre em Linguística pela Eduardo Mondlaine

Professora do Departamento de Línguas Banto da Universidade Eduardo Mondlaine

E-mail: ch_ezra@yahoo.com.br

\section{RESUMO}

Neste trabalho investigamos a alternância pronominal nós/a gente na realização de P4 no Português do Brasil. Seguindo os princípios da Sociolinguística Quantitativa Laboviana foram controladas variáveis linguísticas e sociais a fim de identificar que fatores condicionam o emprego de um ou outro pronome. Esse estudo focaliza o uso alternado dos pronomes em alusão, de falantes nativos da Costa da Lagoa, região não urbana da cidade de Florianópolis, Santa Catarina. Para realizar o trabalho, seguimos a metodologia da Sociolinguística Quantitativa Laboviana, analisamos um corpus de amostra sincrônica de língua falada do PB constituído de quatro entrevistas realizadas na Costa da Lagoa. Duas dessas entrevistas foram realizadas no âmbito do curso de Sociolinguística desenvolvido no segundo semestre do ano de dois mil e quatorze, no programa de Pós-graduação em Linguística da Universidade Federal de Santa Catarina e as outras duas entrevistas utilizadas são oriundas da amostra de Monguilhott (2009), o qual integra o banco de dados do projeto Variação Linguística na Região Sul do Brasil (VARSUL-Santa Catarina). Os dados coletados foram codificados e analisados estatisticamente com recurso do pacote estatístico Goldvarb X. Nossos resultados permitem-nos afirmar que a alternância pronominal nós/a gente para a realização de P4 no PB é condicionada linguisticamente pelo Preenchimento do sujeito e pelo Grau de determinação do referente sujeito, sendo que o sujeito preenchido e o referente sujeito mais genérico e indefinido favorecem essa realização pelo pronome a gente.

Palavras-chave: Alternância pronominal. Realização de P4. Florianópolis. 


\section{ABSTRACT}

In this paper we investigate the pronominal alternation nós / a gente in making of P4 in Portuguese of Brazil. Following the Labovian principles of Quantitative Sociolinguistics there were controlled linguistic and social variables in order to identify factors that influence the use of one or another pronoun. This study focuses on the alternate use of pronouns in reference, native speakers of Costa da Lagoa, a non-urban area of the city of Florianópolis, Santa Catarina. To do the work, we follow the Labovian methodology of Quantitative Sociolinguistics, analyzing a sample of synchronic corpus of spoken language of PB consisting four interviews in Costa da Lagoa. Two of these interviews were conducted in the course of Sociolinguistics developed in the second half of the year 2014 at the Graduate Program in Linguistics at the Federal University of Santa Catarina and the other two interviews used were derived from the Monguilhott sample (2009), which integrates the database project Language Variation in Southern Brazil (VARSUL-Santa Catarina). The collected data were coded and analyzed statistically using as resource the statistical package Goldvarb X. Our results allow us to state that the pronominal alternation nós la gente to perform P4 in BP is linguistically conditioned by the Fill of the Subject and by the Determination Degree of the Related Subject; so the completed subject and the related subject, more generic and indefinite, favor this achievement pronoun a gente.

Keywords: Pronominal alternation. P4 of accomplishment. Florianópolis.

\section{INTRODUÇÃO}

Interessa à Sociolinguística compreender como o sistema linguístico continua a funcionar e ser usado eficientemente pelos falantes enquanto muda e como as formas linguísticas carregam, entre outros significados, significados sociais (WEINREICH; LABOV; HERZOG, 2006 [1968]).

É nesse sentido que o estudo ora apresentado se desenvolve a partir da Teoria da Variação e Mudança Linguística (TVM) (Cf. WEINREICH; LABOV; HERZOG, 2006 [1968]). Por isso, interessa-nos compreender uma possível mudança no quadro pronominal do Português do Brasil (PB), com foco na marcação da primeira pessoa do plural (P4) (Cf. CÂMARA JR, 2011).

Este trabalho, de caráter preliminar, objetiva investigar o fenômeno da alternância dos pronomes nós/a gente, na expressão de $\mathrm{P} 4$, nas variedades sociolinguísticas de falantes nativos da Costa da Lagoa, área não urbana da cidade de Florianópolis, em Santa Catarina. Com isso pretendemos refletir sobre os grupos de fatores linguísticos e extralinguísticos que possam estar condicionando a variação na expressão de P4 no PB. 
A denominação de Costa da Lagoa resulta da topografia da localidade, sendo esta uma costa situada na parte interna de uma lagoa (MONGUILHOTT, 2009). Segundo Monguilhott (2009) a freguesia foi fundada em 20 de junho de 1750. Assim, a Costa da Lagoa se situa na região noroeste da cidade de Florianópolis (CARUSO, 2010). A localidade apresenta um relevo acidentado. O único acesso terrestre é através de caminhos que ligam a localidade à Lagoa da Conceição, passando pelo Canto dos Araçás até o Saco Grande, passando pelas montanhas e o bairro de Ratones (Cf. WIKIPEDIA, 2015). O principal acesso é feito por embarcações pelo Rio Vermelho ou pela Lagoa da Conceição.

Segundo essa mesma autora, em termos de perfil socioeconômico, a localidade caracteriza-se por apresentar uma população bastante integrada entre si, todos os habitantes se conhecem, sabem onde os seus vizinhos moram e as atividades que realizam. Ou seja, a convivência no dia-a-dia é bastante acentuada. Monguilhott (2009, p. 107) afirma, igualmente, que na localidade "as famílias ainda dividem o terreno como é costume em zonas menos urbanas, já que os filhos casam e continuam morando no terreno dos pais." A maior parte dos moradores casa-se entre si, o que segundo a autora facilita ainda mais a integração. Nas informações obtidas a partir das entrevistas que realizamos e, de acordo com as observações de Monguilhott (2009), os moradores participam nas atividades do bairro, tais como: festas, reuniões, discussões dos assuntos da comunidade, etc.

O bairro possui um núcleo de educação infantil municipal. A maior parte dos moradores frequenta o ensino fundamental na Lagoa da Conceição e o Ensino Médio é feito, em geral, nas escolas do Centro de Florianópolis.

No verão o bairro recebe visitantes que frequentam os poucos restaurantes existentes e fazem passeios de barco. Alguns moradores são proprietários desses restaurantes e outros trabalham neles como empregados. Outros moradores ainda vivem da produção agrícola e pesqueira (MONGUILHOTT, 2009). Os restaurantes são mais movimentados no verão, sendo que no inverno o movimento diminui consideravelmente, o que leva muitos moradores a trabalharem fora do bairro nesse período.

$\mathrm{Na}$ Costa da Lagoa não há locais de hospedagem, como hotéis, pousadas nem comércio (MONGUILHOTT, 2009). Segundo Monguilhott este fato faz com que alguns moradores, poucos, aluguem suas casas para veranistas. A autora também salienta que este aluguel, muitas vezes, é feito mediante referências, pois os moradores valorizam muito a tranquilidade existente no bairro e mostram-se satisfeitos com a vida pacata que levam. Uma das coisas que também notamos durante a realização das entrevistas é que eles preservam muito a natureza e a limpeza do local. 
Caracterizado o lócus de realização dessa pesquisa, consideramos relevante refletir, na seção seguinte, sobre os debates que têm tratado das variantes por meio das quais $\mathrm{P} 4$ se realiza no $\mathrm{PB}$, com foco na forma linguística a gente.

\section{ESTUDOS ANTERIORES SOBRE A ALTERNÂNCIA PRONOMINAL NÓS/A GENTE}

É importante aqui retomarmos alguns conceitos a fim de subsidiar a questão que nos propomos a abordar, qual seja: a alternância no uso das formas pronominais nós/a gente como marcação de P4 no PB. Assim, uma primeira questão a ser retomada é o tratamento da forma a gente como pronome pessoal. Segundo Said Ali (1969 apud BRUSTOLIN, 2009, p. 24) "pronome é a palavra que denota o ente ou a ele se refere". Para esse autor "os pronomes pessoais denotam as três pessoas do discurso: o indivíduo que fala ( $1^{\mathrm{a}}$ pessoa), o indivíduo com quem se fala ( $2^{\mathrm{a}}$ pessoa) e a pessoa ou coisa de que se fala ( $3^{\text {a }}$ pessoa)" (SAID ALI, 1969 apud BRUSTOLIN, 2009, p. 24).

Câmara Júnior (2011) defende que a noção de pronome se expressa pela heteronímia e não pela flexão. Afirma também que a função básica do pronome é indicar a noção de pessoa, ou seja, "há um falante - eu, que pode associar a si uma ou mais pessoas - nós, constituindo a primeira pessoa do singular, ou P1, e a primeira pessoa do plural, ou P4". (CAMARA JUNIOR, 2011, p. 17, grifos do autor.). É a partir dessas definições que, ancoradas nos trabalhos de Câmara Junior (2011), principalmente no seu estudo Estrutura da língua portuguesa, propomos o estudo da forma linguística a gente, como forma inovadora na marcação de P4 no PB.

Na obra supracitada o autor apresenta o seguinte sistema pronominal do Português: P1(eu), P2 (tu), P3(ele/ela) P4 (nós), P5 (vós) P6 + /S/- (ele/ela)/S/. Em seguida, o autor alerta que este "quadro é, a rigor, puramente teórico; e em nenhuma região da língua portuguesa ele se realiza exatamente". (CÂMARA JÚNIOR, 2011, p.18). Este alerta do autor aplica-se para o sistema pronominal do PB, pois atualmente, segundo Rubio (2012), observa-se uma mudança em progresso no quadro pronominal do PB com uso alternado das variantes nós e a gente para a realização de $\mathrm{P} 4$.

A partir dessas considerações torna-se relevante também refletirmos sobre que tratamento as gramáticas de Língua Portuguesa têm dado à forma linguística a gente, bem como observarmos como tem sido abordada (ou não) a alternância pronominal na realização de P4. Sobre a forma a gente, Omena (1996a) afirma que:

No Português falado, a forma a gente, do substantivo feminino latino gens, gentis, pode, conforme forma original, ser usada como substantivo, para nomear de forma coletiva, indeterminadora, mais ou menos geral, um agrupamento de seres humanos, identificados, entre si, por objetivos, ideias, qualidades, nacionalidade ou posição (OMENA, 1996a, p. 188 , grifos da autora). 
Para Brustolin (2009), apesar de o pronome a gente estar sendo usado em diversas situações de comunicação, as gramáticas não o validam no quadro pronominal do PB. Para ilustrar tal afirmação a autora comenta que Said Ali (1969), por exemplo, no capítulo dedicado aos pronomes, nada comenta sobre o uso alternado dos pronomes nós/a gente. $\mathrm{O}$ autor destaca apenas gente $^{1}$ no capítulo referente à concordância, como substantivo. Em artigo intitulado Pessoas indeterminadas, Said Ali se refere ao a gente como variação no PB, classificando-o como pronome indefinido, que pode ser usado como sujeito psicológico, no sentido de pessoa ou pessoas indeterminadas. Por sua vez, Cunha e Cintra (1985 apud OMENA, 1996a, p. 189) chamam a forma a gente por "fórmula de representação da $1^{a}$ pessoa, empregada no uso coloquial normal por nós e, também, por eu [...]"

Brustolin (2009) analisou também, as gramáticas de Bechara (1999), Rocha Lima (1972) e Hermínio Sargentim (sem data). Segundo a autora, de uma forma geral, estes autores e outros não mencionados possuem uma postura tradicional e rígida sobre o uso do pronome a gente e, consequentemente, do seu uso alternado com o pronome nós, ignorando aquele. No que respeita a Bechara, ao retomarmos a obra analisada por Brustolin (2009) notamos que este autor, já em 1999, em Moderna Gramática Portuguesa, começa a ponderar uma possível ocorrência de a gente como pronome, ao colocar nas suas observações o seguinte: “O substantivo gente, precedido do artigo a e em referência a um grupo de pessoas em que se inclui a que fala, ou a esta sozinha, passa a pronome e se emprega fora da linguagem cerimoniosa" (BECHARA, 1999, p. 166, grifo do autor). Ao nosso ver, isso, de alguma forma, faz com que sua postura sobre o uso de a gente como pronome não seja tão rígida, como afirmava Brustolin (2009).

Diante disso, concordamos com Lopes (2007, apud BRUSTOLIN, 2009, p. 26) quando afirma que:

As Gramáticas normativas e os manuais didáticos, que raramente explicam fenômenos já consagrados na linguagem coloquial, não apresentam uma posição coerente, única quando se referem à forma a gente. A classificação é, em geral, controvertida, pois ora consideram a gente como 'fórmula de representação da $1^{a}$ pessoa', forma de tratamento, pronome indefinido ou, recurso para indeterminar o sujeito.

Cabe aqui nos perguntarmos o que os estudos sociolinguísticos dizem sobre tal questão. Segundo Rubio (2012) e Brustolin (2009), estudos como os de Fernandes e Görski (1986), Lopes (1993, 1998, 1999, 2007), Naro, Görski e Fernandes (1999), Omena (1986, 1996, 1998, 2003), Omena e Braga (1996), principalmente os de cunho variacionista, mostram que de fato, "a forma inovadora a gente vem superando a forma nós na língua falada nos últimos anos. Embora tal processo não constitua ainda uma mudança completamente operada no PB” (BRUSTOLIN, 2009, p. 27). 
Já Leite, Guedes e Cardoso (2013) afirmam que em observação às pesquisas realizadas, nota-se que o uso de nós e a gente é bastante recorrente no PB, apresentando-se muito mais como uma mudança do que uma variação estável. Sobre isso, Rubio (2012, p. 100) remata: “As gramáticas normativas mais modernas aludem à substituição de nós por a gente no português brasileiro, fenômeno facilmente verificado na língua falada, evidenciado em canções populares e até mesmo na língua falada." Contudo, como vimos, mesmo entre linguistas e filólogos contemporâneos da Língua Portuguesa, ainda não há consenso sobre a classificação estrutural da forma a gente, havendo quem a considere mais próximos de sintagmas nominais que de pronome (Cf. RUBIO, 2012).

Ao discutir este assunto, Omena (1996a) afirma que por extensão de uso, a forma a gente passou a se aplicar, também, sempre ou quase sempre, determinada pelo artigo, para designar a primeira pessoa do discurso, no singular e no plural. Isto fez com que se modificasse a forma a gente, quer do ponto de vista semântico, quer do ponto de vista gramatical, pois segundo essa autora:

Semanticamente, acrescenta-se ao significado, originalmente indeterminador, a referência à pessoa que fala, deiticamente determinada; gramaticalmente, a forma deixa de ser substantivo e passa a integrar o sistema dos pronomes pessoais, conservando porém com o verbo a mesma relação sintática de terceira pessoa gramatical (OMENA, 1996a, 188).

Hopper (1991 apud RUBIO, 2012, p.101) afirma que “novas 'camadas' emergem em um domínio funcional, sem que formas antigas sejam substituídas imediatamente, proporcionando coexistência de camadas novas e antigas no mesmo domínio, as quais codificam funções semelhantes ou idênticas e compõem diferentes variantes". Acreditamos que isto é o que ocorre, atualmente, com as variantes nós e a gente no PB. Esta nossa posição sustenta-se em, entre outros, Omena e Braga (1996, apud RÚBIO, 2012, p. 102), as quais defendem que a forma a gente passa a coexistir com o pronome nós, deixando, gramaticalmente, de ser forma substantiva para integrar o sistema dos pronomes pessoais, constituindo, desta forma, um caso claro de gramaticalização.

\section{PROCEDIMENTOS DE ANÁLISE}

A variável dependente nesse estudo é a alternância pronominal de nós/a gente na marcação de P4 no PB. Desse modo, interessava-nos saber: a) Que grupos de fatores linguísticos condicionam a alternância pronominal de nós/a gente na expressão de P4 no PB? b) A alternância das variantes realiza-se de formas distintas entre indivíduos, e falantes com escolaridade e faixa etária diferentes? 
A partir da leitura de trabalhos já realizados sobre essa temática tínhamos como uma das hipóteses neste estudo que a alternância pronominal de nós/a gente na expressão de P4 no PB é condicionada por fatores linguísticos como grau de determinação do referente sujeito, tempo e modo verbais (Cf. RUBIO, 2012) e preenchimento do sujeito (BRUSTOLIN, 2009).

Acreditávamos também que a forma a gente seria mais empregada por informantes menos escolarizados e mais jovens (RUBIO, 2012; OMENA, 1996b), ou seja, os fatores sociais como escolaridade e idade poderiam ser condicionantes importantes para a realização dessa variante linguística. Assim, para apreender quais as restrições que favorecem o uso de um ou outro pronome pessoal estabelecemos como variáveis linguísticas independentes: o Grau de determinação do referente sujeito, o Tempo e modo verbal e o Preenchimento do Sujeito e como variáveis extralinguísticas ou sociais observamos os grupos de fatores: Escolaridade, Idade e Indivíduo.

A partir da metodologia da Sociolinguística Quantitativa Laboviana analisamos um corpus de amostra sincrônica de língua falada do PB constituído de quatro entrevistas realizadas na Costa da Lagoa, localidade de zona não urbana da cidade de Florianópolis. Duas dessas entrevistas foram realizadas no âmbito do curso de Sociolinguística desenvolvido no segundo semestre do ano de dois mil e quatorze, no programa de Pós-graduação em Linguística da Universidade Federal de Santa Catarina. Nessa disciplina foram estudados os princípios teóricos e metodológicos da TVM, a partir dos quais, como exercício prático de inserção na pesquisa Sociolinguística Variacionista, um grupo de estudantes realizou entrevistas em dois bairros não urbanos da cidade de Florianópolis: A Costa da Lagoa e O Ribeirão da Ilha.

Das entrevistas realizadas no primeiro bairro é que utilizamos duas para a constituição de nossas células sociais. As outras duas entrevistas utilizadas para a composição dessas células são oriundas da amostra Monguilhott (2009), a qual integra o banco de dados do projeto Variação Linguística na Região Sul do Brasil (VARSUL-Santa Catarina).

Os dados coletados foram codificados e analisados estatisticamente com recurso do pacote estatístico Goldvarb X. A seguir apresentamos nossas células sociais:

\section{Quadro 1: Estratificação dos informantes}

\begin{tabular}{|c|c|c|c|c|}
\hline LOCALIDADE & INFORMANTE 1 & INFORMANTE 2 & INFORMANTE 3 & INFORMANTE 4 \\
\hline $\begin{array}{c}\text { Costa da } \\
\text { Lagoa }\end{array}$ & $\begin{array}{c}\text { Menos escolarizado, } \\
\text { Menos jovem }(\mathrm{M})\end{array}$ & $\begin{array}{c}\text { Menos escolarizado, } \\
\text { Menos jovem }(\mathrm{M})\end{array}$ & $\begin{array}{c}\text { Mais escolarizado, } \\
\text { Mais jovem }(\mathrm{F})\end{array}$ & $\begin{array}{c}\text { Mais escolarizado, } \\
\text { Mais jovem (F) }\end{array}$ \\
\hline
\end{tabular}

Fonte: Dados da Pesquisa 


\subsection{O CONTROLE DAS VARIÁVEIS SOCIAIS NA INVESTIGAÇÃO DA ALTERNÂNCIA DE NÓS/A GENTE PARA A REALIZAÇÃO DE P4 NO PB}

Nesta parte do trabalho explicamos, brevemente, as variáveis que nos propomos a controlar. Segundo Tarallo (2004 apud BRUSTOLIN, 2009, 142) "Variáveis independentes sociais ou extralinguísticas são aquelas que levam em consideração os aspectos socioculturais dos informantes". Portanto, iremos abordar as variáveis: Faixa Etária, Escolaridade e Individuo.

No que diz respeito ao grupo de fatores referente a variável social Faixa Etária (mais jovem/menos jovem), estudos como os de (BRUSTOLIN, 2009; OMENA, 1996a; 1996b; LOPES, 1998), afirmam que este fator tem, em geral, sido preponderante para o uso alternado de nós/a gente. Num dos seus estudos, Omena (1996b) afirma que dados por ela analisados mostraram nitidamente que a idade influi na alternância nós/a gente no sentido de os falantes mais velhos usarem mais a forma nós e os mais jovens a forma a gente. A autora mostra também que "os falantes nascidos a partir de aproximadamente 1960 usam mais a forma a gente" (OMENA, 1996b, p. 312). Nossos dados, porém, apresentaram uma situação atípica, pois os informantes categorizados como menos jovens s apareceram como os que mais usam a gente. Contudo, há de se considerar que um dos falantes menos jovens é nascido após 1960, o que pode, em parte, explicar essa atipicidade nos resultados em relação a resultados das investigações anteriores já realizadas sobre o tema.

Outra variável social que foi controlada foi o grupo de fatores Escolaridade (menos escolarizado/mais escolarizado), no qual analisamos a alternância de uso de nós/a gente em função da escolaridade dos informantes. Estudos anteriores atestam que "O pronome a gente, de acordo com algumas pesquisas, é mais empregado em situações informais, enquanto o pronome nós é predominante em situações mais formais" (OMENA, 1986; LOPES, 1993; FERNANDES, 2004 apud BRUSTOLIN, 2009, 161, grifos da autora). Reforçando esta posição, Brustolin (2009), investigando o uso de a gente em contexto escolar, tanto nas práticas orais quanto na escrita, defende que nas escolas, na fala, em todas as séries o pronome a gente suplanta a forma nós. A nossa hipótese com relação a essa variável indicava que os mais escolarizados usariam menos a gente dando preferência ao emprego do pronome nós na realização de P4, enquanto os menos escolarizados dariam preferência ao emprego do pronome a gente nessa função.

Após as rodadas estatísticas, apesar de os nossos dados confirmarem que, de fato, os mais escolarizados usam, preferencialmente, o pronome nós, e os menos escolarizados o pronome a gente, na realização de $\mathrm{P} 4$, verificou-se também que não ocorrem grandes diferenças em termos percentuais no uso desses pronomes, uma vez que se observou o uso elevado do pronome a gente 
por ambos grupos. Isso pode ser considerado um indício de que a variante a gente está suplantando o uso da variante nós na realização de $\mathrm{P} 4$ no $\mathrm{PB}$, demonstrando que a avaliação sobre a alternância pronominal nesta função mudou, pois já não se observa qualquer estigma no uso de tal variante, isto é:

[...] podemos perceber que existe pouco estigma em relação ao pronome a gente no $\mathrm{PB}$. $\mathrm{O}$ que é condenado na maioria dos casos em Florianópolis é o uso da concordância não canônica com os pronomes nós e a gente, ou seja, a gente acompanhado da marca morfêmica -mos e nós acompanhado da marca morfêmica $\varnothing$ (BRUSTOLIN, 2009, p. 196, nota de rodapé).

Outra variável social controlada foi a variável Indivíduo. Ressaltamos que, inicialmente, esta variável não estava inclusa no nosso envelope de variação. À posterior, decidimos incluí-la como forma de enriquecer os dados para análise e também para melhor explicar a situação atípica verificada nos resultados apresentados na variável Faixa Etária.

Assim, avaliamos necessário controlar os dados produzidos por cada informante a fim de verificar como ocorre a alternância pronominal no uso de nós/a gente para a realização de P4, por indivíduo. Temos a destacar para este fator, a escassez de estudos que o controlam.

Realizadas as rodadas estatísticas, embora tenham sido controlados os três grupos de fatores acima descritos, o pacote estatístico selecionou como mais relevante para o condicionamento da realização de $\mathrm{P} 4$, na forma linguística a gente, apenas o grupo de fatores Indivíduo.

\subsection{O CONTROLE DAS VARIÁVEIS LINGUÍSTICAS NA INVESTIGAÇÃO DA ALTERNÂNCIA DE NÓS/A GENTE PARA A REALIZAÇÃO DE P4 NO PB}

As variáveis linguísticas controladas nesse estudo foram Grau de determinação do referente sujeito, Tempo e Modo verbal e Preenchimento do sujeito. Consideramos que seria importante observar o Grau de determinação do referente sujeito em função de que trabalhos como de Lopes (1998), Brustolin (2009), Rubio (2012) apontam para a relevância de tal fator como condicionante linguístico na alternância pronominal (AP) para realização de P4.

Em investigação realizada no interior de São Paulo, Rubio (2012), por exemplo, identificou que "esse grupo de fatores é relevante para AP e também para a CV com o pronome $a$ gente, revelando que sujeitos mais específicos e definidos exercem influência positiva em relação à aplicação de desinência de 1PP [P4]” (RUBIO, 2012, p. 145, grifo nosso). Nesse mesmo sentido, Brustolin $(2009$, p.142) trata da referência dos nós/a gente, a qual pode realizar-se das seguintes maneiras: eu+interlocutor; eu $+3^{\mathrm{a}}$ pessoa, eu + eu genérico. De acordo com esses 
autores, e é com esta hipótese que conduzimos nossa investigação, a gente seria usado para se referir a um número não limitado de sujeitos ou, conforme Lopes (1998), indicaria o grau máximo de indeterminação. Assim, seguindo a terminologia de Rubio (2012) controlamos esse fator considerando que o Grau de determinação do referente sujeito pode se realizar como:

a) Referência genérica e indefinida: o pronome remete a uma categoria generalizada e indeterminada de indivíduos, normalmente com referência a pessoas ou a grupos; b) Referência genérica e definida: o pronome remete a uma categoria generalizada, mas determinada de indivíduos. Nesse contexto fica claro que o falante tem consciência de um determinado grupo de indivíduos no qual ele próprio está incluso; c) Referência específica e definida: o pronome remete a uma categoria específica e determinada de indivíduos em que o falante se inclui junto a outro referente também específico. A recuperação do referente é feita com exatidão no contexto evidenciado em períodos anteriores ou posteriores (RUBIO, 2012, p. 145).

Vejamos alguns exemplos dessa variável em nossos dados:

a) Referência genérica e indefinida:

[...] se você vai falar com um gaúcho, claro que a gente já nota direto né? [o sotaque]. $(01 M-j-e)^{2}$

[...] isso aí sabe o que é que acontece, nós né? somo brasileiro, logo ser humano, ser humano são curioso. (02M-j-e)

b) Referência genérica e definida

[...] então o último horário que a gente tem hoje na Costa é o de onze e meia da noite. $(03 F+j+e)$

Você vê, sinceramente você vê. Nós temo aqui mil e poucas família ninguém tem posto policial aqui. (02M-j-e)

c) Referência específica e definida

[..] nós, jovens, um sempre convida o outro. $(04 F+j+e)$

[...] o meu avô ele mora aqui, pai da minha mãe né? ele mora. Por semana, dois três dias, tenho que passar lá, semana que não vamo e ele tá aí, eu e a minha mãe, a gente não se sente bem. $(04 F+j+e)$

Ao observar a variável Tempo e modo verbal o objetivo era "constatar a que tempo verbal cada uma das formas é mais utilizada" (BRUSTOLIN, 2009, p. 188). Os dados de Brustolin atestaram uma tendência maior ao uso de nós com tempos mais marcados (pretérito perfeito) e de 
a gente com as formas menos marcadas (presente). Rubio (2012, p.146), atesta em seu trabalho, bem como a partir dos trabalhos de Fernandes; Gorski (1986), Omena (1986) e Lopes (1998) as mesmas expectativas assinaladas por Brustolin (2009). O autor afirma que “[...] o pronome nós tem seu uso mais vinculado a verbos no pretérito e o pronome a gente a verbos no presente" (RUBIO, 2012, p. 147).

Com base nesses pressupostos e na metodologia adotada por Rubio (2012) o estudo desse fator foi controlado observando as variantes: do modo Indicativo, os tempos presente, pretéritos perfeito e imperfeito, futuro do presente e futuro do pretérito; do modo subjuntivo, os tempos presente, pretérito e futuro e infinitivo pessoal. Como não houve nenhuma ocorrência com dados do pretérito do subjuntivo, pouquíssimas com Futuro do pretérito do indicativo e presente e futuro do Subjuntivo, agrupamos esses fatores do seguinte modo: Presente (do indicativo e do subjuntivo), Pretérito Perfeito do indicativo, Pretérito Imperfeito (do subjuntivo e do indicativo), Futuro (do presente e do pretérito do indicativo) e infinitivo pessoal. Ilustramos a seguir as ocorrências observadas em nossos dados:

d) Presente do indicativo e do subjuntivo

[...] ah não sei a gente já mora há tanto tempo aqui. (01M-j-e)

[...] isso aí sabe o que é que acontece, nós né? somo brasileiro, logo ser humano, ser humano são curioso. (02M-j-e)

[...] e as pessoas que vêm de fora vão contribuindo mais para que a gente vá, assim, mas tem uma estrutura. (02M-j-e)

e) Pretérito imperfeito do indicativo

[...] a gente queria brincar na rua ao ar livre. $(04 F+j+e)$

[...] porque nós duas tínhamos medo de ficar por causa do boi. $(03 F+j+e)$

f) Pretérito perfeito do indicativo

[...] é, nós fomos a primeira turma que fomos para o Centro, a estudar no Centro. $(03 F+j+e)$

[...] agora é como se fosse uma recompensa porque a gente conseguiu passar por isso tudo, né? $(03 F+j+e)$ 
g) Futuro do presente, futuro do pretérito do indicativo, futuro do subjuntivo

[...] eu disse vamo fazer o que né? (01M-j-e)

Muita família aqui vive de turismo. Se não fosse o turismo o que seria de nós? $(02 M-j-e)$

[...] claro que é bom a vinda deles senão a gente não investiria. (01M-j-e)

[...] lá um dia talvez que a gente for lá vai ser a mesma coisa. (02M-j-e)

h) Infinitivo pessoal

[...] mas sempre ficava um, para acompanhar nós duas $(03 F+j+e)$

[...] não tinha mais nada pra gente fazer, ia fazer o que? $(04 F+j+e)$

Com a variável Preenchimento do Sujeito procuramos verificar qual das formas eleitas pelos falantes para se referir a $\mathrm{P} 4$, sujeito nulo e sujeito preenchido (este último realizado, alternadamente, por nós/a gente) mais favoreceria a realização de a gente. Muitos estudos realizados no Brasil indicam que "o sujeito nulo é cada vez menos uma característica de nossa língua” (BRUSTOLIN, 2009, p. 145).

Nossa hipótese, neste caso, seguindo os resultados de Brustolin (2009) e Rubio (2012), era de que o sujeito preenchido se realizaria, predominantemente, com o pronome a gente, posto que este geralmente acompanhe P3. E consideramos que o sujeito nulo se realizaria com o pronome nós, uma vez que este acompanhe P4 com o morfema distintivo da desinência de plural -mos. Abaixo alguns exemplos dos dados analisados:

i) Sujeito preenchido

[...] a gente tinha sala dos professores que era na oficina de arte. $(03 F+j+e)$

Eu acho que a única coisa aqui que nós não temos, sentimos falta, é um ginásio, um ginásio de esporte. $(04 F+j+e)$

j) Sujeito nulo

[...] aí o que fizemo, peguemo duas telha, peguemo um facão, fomo no coisa, no atajuveira. $(02 M-j-e)$

[..] aqui todos são amigos, então né? aqui trabalhamo todo mundo junto. (01M-j-e)

Linguagens - Revista de Letras, Artes e Comunicação ISSN 1981-9943 Blumenau, v. 10, n. 1, p. 144-160, jan./abr. 2016 
Embora tenhamos realizado as rodadas estatísticas com dados de todos os fatores controlados, apenas três grupos de fatores foram selecionados pelo programa GOLDVARB X como relevantes no condicionamento da alternância pronominal nos/a gente.

Analisaremos, na seção seguinte, os resultados oriundos apenas da rodada geral na ordem de relevância dos grupos de fatores apresentada pelo pacote estatístico: Grau de determinação do referente sujeito, Preenchimento do sujeito e indivíduo. Os outros grupos de fatores controlados (escolaridade, faixa etária e o linguístico, tempo e modo verbal) não foram considerados pertinentes na rodada global.

\section{RESULTADOS E DISCUSSÕES: ALTERNÂNCIA PRONOMINAL NÓS/ A GENTE NA REALIZAÇÃO DE P4 NO PB}

Feitas as rodadas estatísticas verificou-se, conforme demonstravam as bibliografias estudadas, maior ocorrência da variante a gente em relação a variante nós para a realização de P4 nos contextos analisados. Do total de 278 dados obtidos para P4, 240 foram realizados com a variante a gente e os 38 restantes, com a variante nós. Na tabela 1 apresentamos o percentual de realização de $\mathrm{P} 4$ nos dados analisados.

Tabela 1: Percentual da variante a gente na realização de P4 no PB

\begin{tabular}{l|c|c}
\hline \multicolumn{1}{c|}{ VARIÁVEL } & APLICAÇÃo & PERCENTUAL \\
\hline A gente & 240 & $86 \%$ \\
\hline Nós & 38 & $14 \%$ \\
\hline TOTAL: & 278 & $100 \%$ \\
\hline
\end{tabular}

Fonte: Dados da Pesquisa

Esse resultado corrobora o que já afirmava Omena (1996a) e Leite, Guedes e Cardoso (2013) de uma possível mudança no quadro de pronomes pessoais do PB com a inclusão do pronome a gente na marcação de $\mathrm{P} 4$, posto que "Os diferentes estágios em que pudemos detectar a interferência da forma a gente no sistema pronominal do português parecem evidenciar, apesar de não estarmos tratando com dados de tempo real, uma mudança linguística em progresso" (OMENA, 1996, p. 192). Essa afirmação parte da constatação da autora do grande uso desse pronome em substituição ao pronome nós, o qual parece ter seu uso cada vez mais restrito a contextos muito formais, principalmente na escrita, conforme já afirmava Brustolin (2009).

$\mathrm{Na}$ análise da variável Grau de determinação do referente sujeito observamos que nossa hipótese foi confirmada. Vejamos os dados da tabela 2. 
Tabela 2: Frequência e probabilidade de a gente segundo a variável grau de determinação do referente sujeito

\begin{tabular}{l|c|c|c}
\hline GRAU DE DETERMINAÇÃo DO REFERENTE SUJEITO & APLICAÇãO/TOTAL & PERCENTUAL & PROBABIL. \\
\hline Referência genérica e indefinida & $41 / 42$ & $97,6 \%$ & 0.84 \\
\hline Referência genérica e definida & $121 / 150$ & $80,7 \%$ & 0.44 \\
\hline Referência específica e definida & $78 / 86$ & $90,7 \%$ & 0.38 \\
\hline TOTAL: & $240 / 278$ & $86,0 \%$ & - \\
\hline
\end{tabular}

Fonte: Dados da Pesquisa

Assim como os trabalhos de Lopes (1998) e Rubio (2012), neste atestamos que quanto mais genérica e indefinida for a referência ao sujeito, maior a probabilidade de ocorrer o uso da variante a gente (84) para a realização de P4.

No tocante a variável Preenchimento do sujeito nossa hipótese era de que seria maior a probabilidade de ocorrências da variante a gente com sujeito preenchido. Conforme já ilustraram as análises de Brustolin (2009), Rubio (2012), nossos dados também indicam que o preenchimento do sujeito favorece a realização de P4 pela variante a gente. Ao contrário, se o sujeito é nulo, este será reconhecido pela desinência verbal mos, sendo considerado por nós, neste caso, a realização de P4 pela variante nós. Observe-se os dados na Tabela 3, a seguir:

Tabela 3: Frequência e probabilidade de a gente segundo a variável Preenchimento do sujeito

\begin{tabular}{l|c|c|c}
\hline \multicolumn{1}{c|}{ PREENCHIMENTO DO SUJEITO } & APLICAÇÃO/TOTAL & PERCENTUAL & PROBABIL. \\
\hline Sujeito preenchido & $236 / 264$ & $89 \%$ & 0.55 \\
\hline Sujeito nulo & $4 / 14$ & $29 \%$ & 0.02 \\
\hline TOTAL & $240 / 278$ & $86 \%$ & - \\
\hline
\end{tabular}

Fonte: Dados da Pesquisa

Nota-se que a maioria das realizações de P4 nos dados de nossos informantes foram com sujeito preenchido $(264 / 278)$ e destas, a maioria foi com o pronome a gente $(89 \%)$. Pode-se afirmar que quanto maior o preenchimento do sujeito maior a probabilidade de ocorrência da variante a gente na realização de $\mathrm{P} 4(0.55)$.

Com relação à variável social Indivíduo, conforme já mencionado no item 3.1, esta passou a ser controlada depois que os dados sobre a variável Faixa etária apresentaram resultados contrários ao que a literatura sobre o tema vem demonstrando (Cf. OMENA 1996a; LOPES, 1998; BRUSTOLIN, 2009; RUBIO, 2012), ou seja, que quanto mais velho o informante menor a probabilidade de emprego do pronome a gente para a realização de P4. Contudo, os dados de nossos informantes mostraram que os mais velhos empregam mais o pronome a gente, em relação 
aos mais jovens, para a realização de P4. Diante disso, vejamos os resultados apresentados na Tabela 4, abaixo:

Tabela 4: Frequência e probabilidade de a gente segundo a variável Indivíduo

\begin{tabular}{l|c|c|c}
\multicolumn{1}{c|}{ INDIVÍDUO } & APLICAÇÃO/TOTAL & PERCENTUAL & PROBABIL. \\
\hline Informante 01 & $99 / 104$ & $95 \%$ & 0.82 \\
\hline Informante 02 & $36 / 47$ & $77 \%$ & 0.36 \\
\hline Informante 03 & $35 / 43$ & $81 \%$ & 0.26 \\
\hline Informante 04 & $70 / 84$ & $83 \%$ & 0.26 \\
\hline ToTAL & $\mathbf{2 4 0 / 2 7 8}$ & $\mathbf{8 6 \%}$ & - \\
\hline
\end{tabular}

Fonte: Dados da Pesquisa

Ao analisar a Tabela 4 verificamos que o informante um, apesar de ter como característica ser um informante menos jovem, é o indivíduo que mais emprega o pronome a gente para a realização de P4. Foi o comportamento deste informante, o qual polariza com os demais, que causou, nos resultados referentes à variável Faixa etária, o estranhamento já referido.

Assim, há que se salientar que dois aspectos podem ter contribuído para que o informante um empregasse mais a forma a gente: 1) este informante é menos escolarizado e estudos e hipóteses anteriores (OMENA, 1996b; BRUSTOLIN, 2009; LOPES, 1998) mostram que falantes menos escolarizados empregam, preferencialmente, o pronome a gente para a realização de $\mathrm{P} 4$. Além disso, 2) de acordo com Omena (1996a) a geração de falantes nascidos a partir dos anos 1960 tende a empregar mais a forma a gente do que a forma nós para a realização de P4 no PB e, neste caso, o nosso informante atípico é nascido na década de 1970, o que corrobora a constatação de Omena (1996a).

\section{CONSIDERAÇÕES FINAIS}

Nesse estudo investigamos quais as variáveis sociais e linguísticas condicionam a alternância pronominal nós/a gente na realização de P4 no PB. Elegemos como variáveis independentes nesse estudo as variáveis sociais, Faixa etária e Escolaridade e as variáveis linguísticas, Grau de determinação do referente sujeito, Preenchimento do sujeito e Tempo e Modo verbal. Nossas hipóteses quanto às variáveis sociais eram de que os informantes mais jovens e menos escolarizados empregariam, preferencialmente, a forma linguística a gente para a realização de P4. Quanto às variáveis linguísticas, acreditávamos que o sujeito preenchido, o referente sujeito mais genérico e mais indefinido e o tempo presente do modo indicativo, favoreceriam o maior emprego do pronome a gente para a realização de $\mathrm{P} 4$. 
Entretanto, feitas as rodadas estatísticas, as variáveis independentes sociais por nós estabelecidas não se mostraram relevantes no condicionamento da alternância pronominal nós/a gente. Esse resultado nos levou a realizar nova rodada, acrescentando às variáveis sociais a variável Indivíduo. E dentre as variáveis independentes linguísticas, o grupo de fatores Tempo e modo verbal não foi considerado relevante pelo pacote estatístico para o nosso estudo.

Desse modo, nossos resultados permitem-nos afirmar que a alternância pronominal nós/a gente para a realização de $\mathrm{P} 4$ na amostra investigada com quatro falantes da comunidade da Costa da Lagoa, em Florianópolis/SC, é condicionada linguisticamente pelo Preenchimento do sujeito e pelo Grau de determinação do referente sujeito, sendo que o sujeito preenchido e o referente sujeito mais genérico e indefinido favorecem essa realização pelo pronome a gente. Os dados também revelam a necessidade de nesse tipo de estudo considerar-se a variável social Indivíduo como fator relevante, uma vez que as variáveis sociais, Faixa etária e Escolaridade, tradicionalmente testadas na investigação desse tema, já não se mostram tão relevantes devido ao aumento do emprego do pronome a gente para a realização de P4 no PB, suplantando o pronome nós.

\section{NOTAS}

1 Segundo Brustolin (2009) o autor trata apenas da forma linguística gente e não do pronome a gente.

2 Os códigos para identificação dos traços sociais dos informantes são os seguintes: indivíduo: refere-se ao número do informante na organização dos dados, 01 para informante 01, por exemplo; Sexo: Masculino (M) e Feminino (F); Faixa etária: Mais jovem (+j) e Menos jovem (-j); Escolaridade: Mais escolarizado (+e) e Menos escolarizado (-e).

\section{REFERÊNCIAS}

BECHARA, E. Moderna gramatica portuguesa. $37^{\mathrm{a}}$ ed. revista e ampliada, $15^{\mathrm{a}}$ reimpressão. Rio de janeiro: Lucerna, 1999.

BRUSTOLIN, A. K. B. da S. Itinerário do uso e variação de nós e a gente em escritos e orais de alunos do Ensino Fundamental da Rede Pública de Florianópolis. Florianópolis: UFSC, Programa de Pós-Graduação em Linguística, Dissertação de Mestrado em Linguística, 2009.

CÂMARA JÚNIOR, J. M. Estrutura da língua portuguesa. 44ª ed. Petrópolis: Vozes, 2011.

CARUSO, J. P. L. Parentes e casamento: da fuga ao morar junto na Costa da Lagoa. In: SEMINÁRIO INTERNACIONAL FAZENDO GÊNERO: DIÁSPORAS, DIVERSIDADES, DESLOCAMENTOS, 9, 2010, Florianópolis. Anais... Florianópolis: UFSC, 2010.

LOPES, C. R. S. Nós e a gente no português falado culto do Brasil. DELTA, 1998, v. 14, n. 02, pp. 405-422. 
LEITE, C.A.Z. GUEDES, I.C.O.; CARDOSO, V.F. Entre nós e a gente: o Português Brasileiro se afirma. Ave Palavra, 15, 2013/1, pp. 1-14.

MONGUILHOTT, I.O.S. Estudo sincrônico e diacrônico da concordância verbal de terceira pessoa do plural no PB e no PE. 2009. Tese (Doutorado) - Universidade Federal de Santa Catarina. Florianópolis, 2009.

OMENA, N.P.A referência à primeira pessoa do discurso no plural. In SILVA, G.M.O. e SCHERRE, M.M.P. Padrões sociolinguísticos: análise de fenômenos variáveis do português falado na cidade do Rio de Janeiro. Rio de Janeiro: Tempo Brasileiro, 1996a.

As influências sociais na variação entre nós e a gente na função de sujeito. In SILVA, G. M.O.; SCHERRE, M.M.P. Padrões sociolinguísticos: análise de fenômenos variáveis do português falado na cidade do Rio de Janeiro. Rio de Janeiro: Tempo Brasileiro, $1996 \mathrm{~b}$.

RUBIO, C. F. Padrões de concordância verbal e de alternância pronominal no português brasileiro e no português europeu: estudo sociolinguístico comparativo. São Paulo: Cultura Acadêmica, 2012.

WEINREICH, U.; LABOV, W.; HERZOG, M. Fundamentos Empíricos para uma teoria da mudança linguística. São Paulo: Parábola, 2006 [1968].

WIKIPEDIA. pt.m.wikipedia.org. Acesso em: 22/03/15. 